\title{
Spectrophotometric study of the interaction of methylene blue with poly(styrene-co-sodium styrene sulfonate)
}

\author{
Souha Ben Mahmoud ${ }^{1,2}$, Ahmed Hichem Hamzaoui ${ }^{3}$ and Wafa Essafi ${ }^{1, *}$ \\ ${ }^{1}$ Laboratoire Matériaux, Traitement et Analyse - Institut National de Recherche et d'Analyse Physico-Chimique, \\ Pôle Technologique de Sidi Thabet, 2020 Sidi Thabet-Tunisie \\ ${ }^{2}$ Institut National des Sciences Appliquées et Technologie, INSAT, Centre Urbain Nord BP 676- \\ 1080 Tunis Cedex, Tunisie \\ ${ }^{3}$ Laboratoire de Valorisation des Matériaux Utiles - Centre National des Recherches en Sciences des Matériaux, \\ BP 95, Hammam Lif 2050, Tunisie
}

\begin{abstract}
The interaction of the cationic phenothiazine dye, the Methylene Blue (MB) with poly-(sodium styrene sulfonate) $)_{f}$-co-(styrene) $)_{l-f}$, (PSSNa $f$ ), has been investigated by spectrophotometric method. The polyelectrolyte induced metachromasy resulting in a blue shift of the absorption maxima of the dye, in agreement with the formation of dye H-aggregates. The stability of the PSSNa-MB complexes was studied as a function of polyelectrolyte chain length, polyelectrolyte electrostatic charge density $f$, polyelectrolyte concentration, $\mathrm{NaCl}$ salt addition, tetrahydrofurane (THF) addition and THF treatment. The stoichiometry of PSSNa-MB complex evaluated by the molar ratio method was found $4: 1$ for the fully charged PSSNa $f=1$. Reversal of metachromasy was observed upon salt and THF addition, while THF treatment does not affect the complex and allows recovering the initial complex. Finally, thermodynamic parameters of the interaction between the polyelectrolyte and the dye at different temperatures, namely free energy $\Delta \mathrm{G}$, the enthalpy $\Delta \mathrm{H}$ and the entropy $\Delta \mathrm{S}$ have been evaluated to determine the binding constant and as a consequence the stability of the complex. The metachromasy effect was found to be more high as the chemical charge $f$ increases and reaches its maximum value $f=1$, when operating at optimal conditions. So, the PSSNa $f=1-\mathrm{MB}$ complex is the most stable in comparison to the others based on lower charge density PSSNa $f$.
\end{abstract}

Keywords: Methylene Blue, poly(styrene-co-sodium styrene sulfonate), metachromatic complex, Thermodynamic parameters, UV-vis Spectroscopy.

\section{Introduction}

The release of colored wastewaters from industry like textile, in effluents can affect among another the viability of aquatic species ${ }^{1}$, that's why water-soluble dyes are very injurious and their presence in water even at low concentrations is visible and undesirable ${ }^{2}$. Their decontamination which is highly required, is based typically on coagulation/flocculation, oxidation and adsorption in combination with biological treatments.

Coagulation/flocculation processes are the most widely used as pretreatments to remove coloring materials and suspended particles, before other treatments such as biological one. The efficiency of the flocculation treatment is based on the interaction between the dye and the flocculant agent, like polyelectrolyte. Numerous investigations have been done to elucidate the interaction between dye and polyelectrolyte of opposite sign, in aqueous solutions $^{3-5}$, by different techniques such as absorbance, fluorescence and circular dichroism yielding significant knowledge ${ }^{6-8}$. Many scientists have pointed the importance of the coulombic electrostatic interactions between polyelectrolytes and dyes. According to the sign of the electrostatic charge dye, the used polyelectrolyte can be polycations $^{9-11}$ or polyanions ${ }^{12-16}$. In addition to coulombic interactions, hydrophobic interactions can contribute to the binding and affect the stability of the complex ${ }^{14,17,18}$.

The binding of dyes with polyelectrolyte is accompanied by changes in the absorbance and/or fluorescence spectrum compared to the individual monomeric molecules. According to Kasha's exciton theory ${ }^{19}$, dyes can be assembled according to $\mathrm{H}$ aggregates ( $\mathrm{H}$ for hypsochromic) which are spectroscopic entities characterized by a blue-shifted 
absorption with respect to monomer absorption, involving a parallel stacking of dye molecules into well-ordered fashion, aligned in face to face arrangement, known as metachromasy. It is so related to the formation of a single individual compound via the interaction of the dye cation and the chromotrope anionic polyelectrolyte. On the other hand, J aggregates can be formed (from Jelly one of the first workers who investigated these shifts) and present however a red-shifted absorption band because of a lowest energy system, where the molecular alignment is edge to edge ${ }^{20}$.

The strength and the stability of such molecular aggregation depend on different physical chemical parameters related either to the dye and to the polyelectrolyte, it can involve the structure of the dye and that of the polyelectrolyte, their concentration, ionic strength, solvent composition ${ }^{21}$,

As flocculent, we focus on typical polyelectrolyte which is Polystyrene sulfonate, having a structural aspect; it bears an aromatic group to which the negative charge is directly attached. Few studies reported the interaction of Polystyrene sulfonate with cationic dye 12,18 and the characteristics of the polyelectrolyte were kept constant during the study.

In the present work, we are interested to analyze in detail the effect of the variation of physical chemical parameters intrinsic to the polystyrene sulfonate such as the polyelectrolyte electrostatic charge density, the chain length, the polyelectrolyte concentration,... on the dye/polyelectrolyte interaction. The chosen cationic model dye is methylene blue. As far as other external parameters related to the solvent such as the ionic force, the effect of added organic solvent tetrahydrofuran "THF" in the aqueous solution, were also investigated and it can be indeed a case encountered in practice for aqueous rejected effluents. Moreover, we introduce another parameter by taking advantage of the possibility offered by THF plus water mixtures: it is possible, after adding THF, to evaporate it and substitute it by water in order to keep the same concentration. We will call this "THF treatment" that was also investigated. Finally, several interaction parameters such as binding constant, stoichiometry of the dye-polyelectrolyte complex and thermodynamic parameters like free energy, enthalpy, and entropy changes were evaluated using polyelectrolyte/dye interactions at different temperatures, in order to evaluate the importance of the polyelectrolyte structural parameters on the polyelectrolyte/dye complex.

\section{Experimental Section}

\section{Polymer synthesis}

The polyelectrolyte used in this study is poly(sodium styrene sulfonate $)_{f}-$ co-(styrene) $)_{1-f}$, abbreviated PSSNa, it is a copolymer of styrene and sodium styrene sulfonate and whose chemical structure is shown on Fig. 1. It was prepared by post-sulfonation of polystyrene $\left(\mathrm{M}_{\mathrm{w}}=280,000 \mathrm{~g}\right.$ $\mathrm{mol}^{-1}$ corresponding to a polymerization index $\mathrm{N}=$ 2692, of batch $n^{\circ} 16311 \mathrm{DB}$ of Sigma-Aldrich Reference 182427) based on the Makowski procedure $^{22,23}$, that enables partial sulfonation and leads to a well-defined polyelectrolyte ${ }^{24}$. The sulfonation rate $f$ of the polyelectrolytes was varied between 0.3 (the limit for solubility in water) and 1 (fully charged). The sulfonation rate $f$ is thus always above the Manning condensation limit for the chemical charge density, which is equal to $\mathrm{a} / \mathrm{l}_{\mathrm{B}} \sim 0.3$ for PSS in water (a, length of one unit, $1_{B} \sim \mathrm{e}^{2} /(\varepsilon k T)$ $\sim 7 \AA$, Bjerrum length in water).

We used also others commercial fully charged PSSNa $f=1$, at different molecular weights $\left(\mathrm{M}_{\mathrm{w}}=20700,148000,666,000 \mathrm{~g} \mathrm{~mol}^{-1}\right.$, their Polydispersity Index $\left.M_{w} / M_{n}<1.2\right)$ purchased from Polymer Standard Service (Mainz, Germany).

The cationic phenothiazine dye, Methylene blue, abbreviated as $\mathrm{MB}$, was purchased from Fluka, $\mathrm{NaCl}$ salt was purchased from Scharlau and THF from Merck. These reagents were used without further purification.<smiles>CCCCCCC(C)c1ccc([N+](=O)[O-])cc1</smiles>

(a)

The sulfonation rate i.e. the electrostatic charge density $f=\mathrm{x} / \mathrm{x}+\mathrm{y}$; the fully charged polyelectrolyte $(f=1)$ corresponds to $\mathrm{y}=0$.<smiles>[CH][N+](C)=c1ccc2nc3ccc(N(C)C)cc3sc-2c1</smiles>

(b)

Figure 1. The chemical structure of the polyelectrolyte (a) and of the methylene blue dye (b) used in this study.

\section{Preparation of solutions}

For all prepared solutions, the water used is deionised $\mathrm{H}_{2} \mathrm{O}$ with a resistivity of $18 \mathrm{M} \Omega . \mathrm{cm}$.

A dye solution of $1 \times 10^{-4} \mathrm{~mol} \mathrm{~L}^{-1}$ and a polyelectrolyte stock solution of $1 \times 10^{-3} \mathrm{~mol} \mathrm{~L}^{-1}$ were prepared separately.

The investigated solution is prepared by adding aliquots of polyelecytolyte solution (ranging from 0 to $6 \mathrm{ml}$ in order to vary the ratio of the polyelectrolyte to dye) to a fixed volume of $2 \mathrm{ml}$ of the dye solution. The final volume of the solution 
was adjusted to $10 \mathrm{ml}$ by adding deionised $\mathrm{H}_{2} \mathrm{O}$, making the final dye concentration in the solution

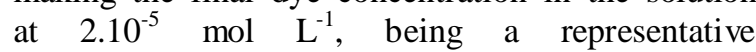
concentration of dyes in aqueous effluents, as also adopted in various previous studies ${ }^{14-15}$.

For salt investigation, different $\mathrm{NaCl}\left(0.2 \mathrm{~mol} \mathrm{~L}^{-1}\right)$ solution volumes were added to the investigated (final) solution.

In case where the solvent is a mixture of $\mathrm{H}_{2} \mathrm{O} / \mathrm{THF}$, the desired amount of THF is added at the latest and letting at rest under stirring for 30 minutes, before investigation. The treatment of the solutions consists in evaporating subsequently THF, under gentle nitrogen flow and substituting it exactly by the same volume of $\mathrm{H}_{2} \mathrm{O}$. So, the polyelectrolyte solutions become in pure $\mathrm{H}_{2} \mathrm{O}$ at the same concentration than initially in the mixture $\mathrm{H}_{2} \mathrm{O}$ /THF.

\section{UV-vis spectroscopy}

Absorption was measured using a LABOMED UV-visible double beam spectrophotometer UVD 3000 , with a matched pair of cells of $1 \mathrm{~cm}$ path length, between 200 and $800 \mathrm{~nm}$. The used Hellma cells have an optical path length of $10 \mathrm{~mm}$.

All measurements were performed at $25^{\circ} \mathrm{C} \pm 0.1^{\circ} \mathrm{C}$ except when we studied the temperature effect.

Absorbance measured at $A_{m}$ refers to the absorbance of the monomeric band and $\mathrm{A}_{\mathrm{M}}$ refers to the absorbance of metachromatic band measured at its maximum centered at $590 \mathrm{~nm}$ for $\operatorname{PSSNa} f=1$ and $600 \mathrm{~nm}$ for PSSNa $f=0.37$. The ratio $\mathrm{A}_{\mathrm{m}} / \mathrm{A}_{\mathrm{M}}$ was plotted against the polyelectrolyte concentration/dye concentration ratio $[\mathrm{P}] /[\mathrm{D}]$.

Note that the value of this ratio is determined within a relative error of $6 \%$.

\section{Results And Discussion}

Effect of polyelectrolyte chain polymerization degree (polyelectrolyte chain length)

In aqueous solution, MB exhibits a band at 665 $\mathrm{nm}$ and a shoulder at $612 \mathrm{~nm}$ which are assigned to monomeric and dimeric forms, respectively. The addition to the aqueous dye solutions of PSSNa $f=1$, for different degrees of polymerization ranging from 38 to 3233 , at $\mathrm{P} / \mathrm{D}=1$ for which the total number of negative charges carried by the polyelectrolyte is equal to the positive charges of the Dye, is shown in Fig. 2a. It emerges that for the first four chain lengths, there is a continuous decrease of the absorption at maximum wavelength (monomer band absorption), followed by, the disappearance of the dimeric band and the appearance of a new band around $590 \mathrm{~nm}$. This new band corresponds to the formation of a single individual compound, i.e. new metachromatic complexes were formed between the cationic dye and the polyelectrolyte 14,25-27, regardless the polyelectrolyte degrees of polymerization. This blue shift in the spectrum is the signature of the formation of dye $\mathrm{H}$-aggregates ${ }^{12,28}$ : as a consequence of their higher local concentration near the polyanion, the dye self-aggregates into wellordered face-to-face parallel stacking, by means of aromatic-aromatic interaction (Scheme 1). Moreover, the maximum intensity of the metachromatic band is centered at about $590 \mathrm{~nm}$, for all polyelectrolyte chain lengths and its intensity increases slightly as the chain length increases, indicating a more efficiency of the dye aggregation as the chain length increases. For the highest chain length, the behavior is reversed and the intensity of the monomeric form increases followed by a decrease of the metachromatic band intensity, resulting in a less efficiency of dye complexation for that large polymerization degree. This evolution as a function of chain polymerization degree can be summarized on Fig. $2 b$, representing the evolution of $A_{m} / A_{M}$ as a function of $\mathrm{P} / \mathrm{D}$ ratio, for different chain lengths of $\operatorname{PSSNa} f=1$. For short chain length $\left(\mathrm{M}_{\mathrm{w}}=7930 \mathrm{~g}\right.$ $\mathrm{mol}^{-1}$ ), the ratio $\mathrm{A}_{\mathrm{m}} / \mathrm{A}_{\mathrm{M}}$ is about 1.07 , while that in pure water is 2.53 , so the dye aggregation is favored in the presence of polyelectrolyte, however the monomeric dye form remains highly dispersed in the solution. As the chain length increases, the ratio $A_{m} / A_{M}$ decreases sharply and remains constant in agreement with a favorable aggregation of the dye on the polyelectrolyte chain. This behavior is found until chain length value of $554.550 \mathrm{~g} \mathrm{~mol}^{-1}$. However, for a higher chain length $\left(\mathrm{M}_{\mathrm{w}}=666.000 \mathrm{~g}\right.$ $\mathrm{mol}^{-1}$ ) the dye-polyelctrolyte interactions become disadvantaged and the dye aggregation becomes more difficult. As a consequence, the ratio $A_{m} / A_{M}$ increases again showing a release of the dye at monomeric form, and so a decrease of metachromatic complex stability. Note that PSSNa polyelectrolyte contains aromatic rings that can undergo aromatic-aromatic interactions with the aromatic dye at short-range scale ${ }^{18}$, in addition to attractive electrostatic interactions. This behavior as a function of chain length is highlighted for the first time according to our knowledge and the increase of the $A_{m} / A_{M}$ ratio for highly chain length can be related to the inhibition locally of the cooperative self-binding tendency of the aromatic dye counterions. Indeed, the ion pairs made of the dye and the polymeric aromatic functional groups become far from each other and so could not aggregate). As a conclusion, there is an optimal of PSSNa chain length to ensure the self-aggregation of the dye. 


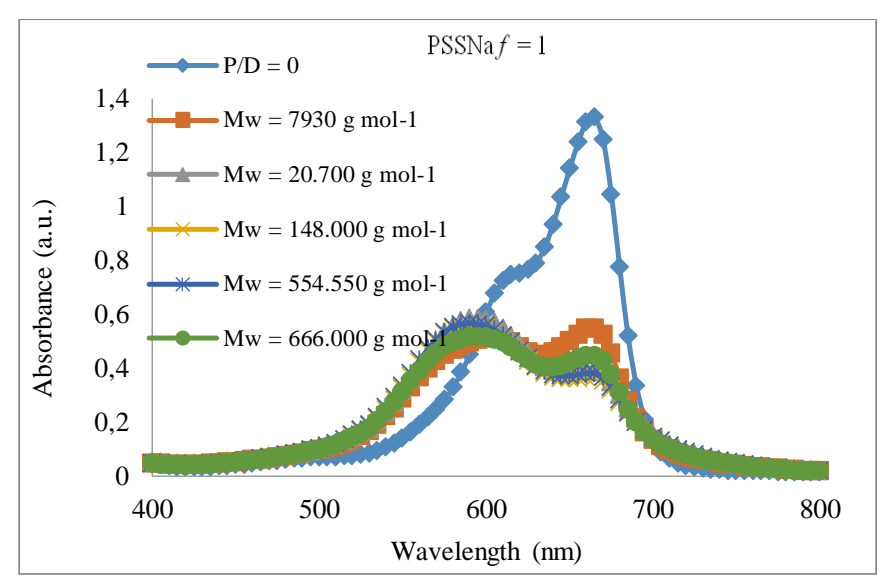

(a)

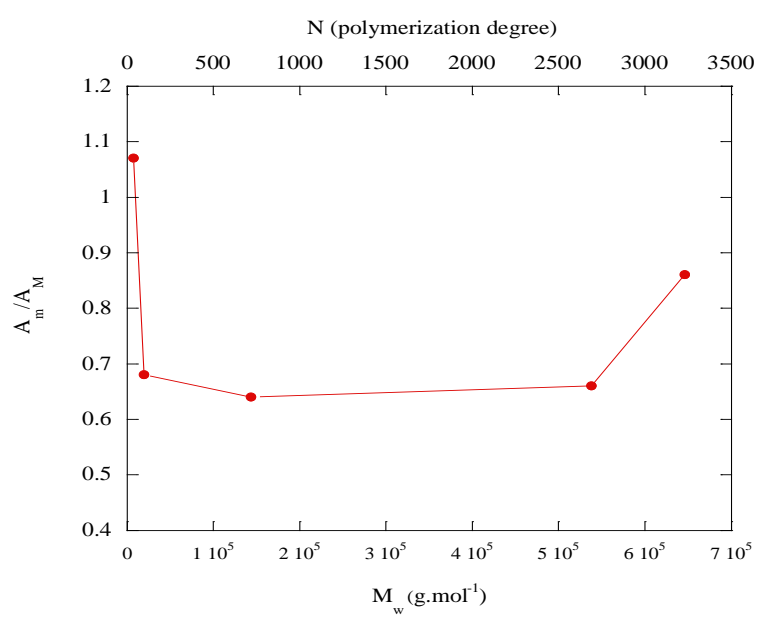

(b)

Figure 2: Absorption spectrum of dye in presence of $\operatorname{PSSNa} f=1$ at different chain polymerization degrees (a), evolution of the corresponding $A_{m} / A_{M}$ as a function of chain polymerization degree, at $P / D=1$ (b).

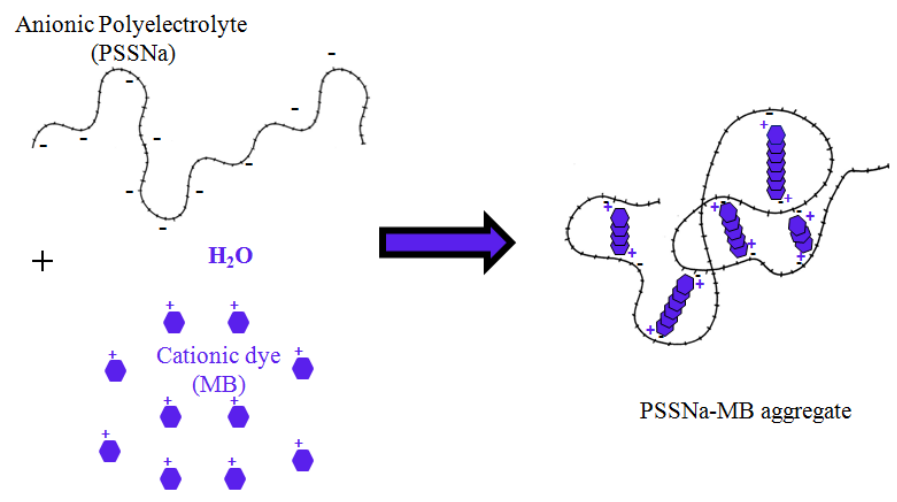

Scheme 1. Schematic representation of PSSNa-MB aggregation

\section{Effect of polyelectrolyte electrostatic charge density $f$}

The electrostatic charge density $f$ of PSSNa is independent of the media composition; we talk about quenched polyelectrolytes or also strong polyelectrolytes which dissociate completely by releasing saline species of zero chemical reactivity (no acidic-basic property) in addition to the macroion formation, independently of the chemical composition of the solvent. Here, the dissociation of PSSNa in water is accompanied by the formation of sodium counterions ions and negative sulfonate groups which have no affinity for protons, since they are the infinite weak conjugate base of the strong sulfonic acid and so preserve their negative charge, regardless the $\mathrm{pH}$ of the medium.

The electrostatic charge density $f$ of PSSNa is varied by modifying chemically the fraction of sulfonated groups bound to the parent polystyrene chain.

However, in the previous studies ${ }^{14-16}$ the electrostatic charge of the polyelectrolyte depends on the $\mathrm{pH}$ of the media; it can be varied by changing the $\mathrm{pH}$ since the used polyelectrolytes were weak such as poly(acrylic acid) or poly(sodium acrylate) presenting the anionic form as the counter ion $\mathrm{H}^{+}$is released, for $\mathrm{pH}$ higher to their $\mathrm{pKa}$. At $\mathrm{pH}<\mathrm{pKa}$ there is no interaction between the dye and the polyelectrolyte, but at $\mathrm{pH}>\mathrm{pKa}$, the attractive interaction between the dye and the polyelectrolyte is established.

We should note that practical point of view; quenched polyelectrolytes are advantageous since their efficiency is $\mathrm{pH}$ independent, considering the fact that the effluent $\mathrm{pH}$ cannot be usually controlled.

Fig. 3a shows the absorption spectra of the MB dye in presence of PSSNa $(\mathrm{N}=2692)$ in aqueous solution at $\mathrm{P} / \mathrm{D}=1$, as a function of charge density $f$ of the polyelectrolyte. Note at that ratio, the total number of negative charges carried by the fully charged polyelectrolyte $(f=1)$ is equal to the positive charges of the dye. However, for lower charge densities $f$, the negative charges of the polyelectrolytes are lower than the total positive 
charges of the dye and this deficiency is even more important as the charge density $f$ is low.

It emerges that as the charge density $f$ increases from 0.37 to 1 at that $\mathrm{P} / \mathrm{D}$ ratio, the intensity of the band related to the monomeric forms decreases, while the intensity of the metachromatic band increases and is displaced to lower wavelengths (blue shift). This behavior is in agreement with a better complexation of the dye with PSSNa as the charge density $f$ increases. In fact, as $f$ increases, the attractive electrostatics interactions between the dye and the polyeleclectrolyte become stronger. Indeed, the negative effective charge of $\mathrm{PSSNa} f=1$ is higher than that of PSSNa $f=0.37^{29}$. This result suggests that the interaction between the dye and the polyelectrolyte involves electrostatic forces ${ }^{30}$.
Similar evolutions were reported for weakly charged polyacids, showing the formation of complex between dye and polyelectrolyte at suitable $\mathrm{pH}$ values ${ }^{14-16}$ where negative electrostatic charge of the polyelectrolyte is sufficient to interact with the cationic dye. Fig. $3 \mathrm{~b}$ shows the evolution of the ratio $\mathrm{A}_{\mathrm{m}} / \mathrm{A}_{\mathrm{M}}$ that decreases as $f$ increases. So, under these conditions and at a constant polyelectrolyte concentration, it seems that the complexation is favored as $f$ increases indicating that the attractive electrostatic interaction constitutes the major force driving the interaction between the polyelectrolyte and the dye. This result is in contrast to what was previously claimed for $\operatorname{PSSNa} f=1$ and rhodamine 6G (composed by more aromatic rings than $\mathrm{MB}$ ) ${ }^{18}$ where the short range aromatic-aromatic interactions were considered as the major force driving the interaction dye-polyelectrolyte.

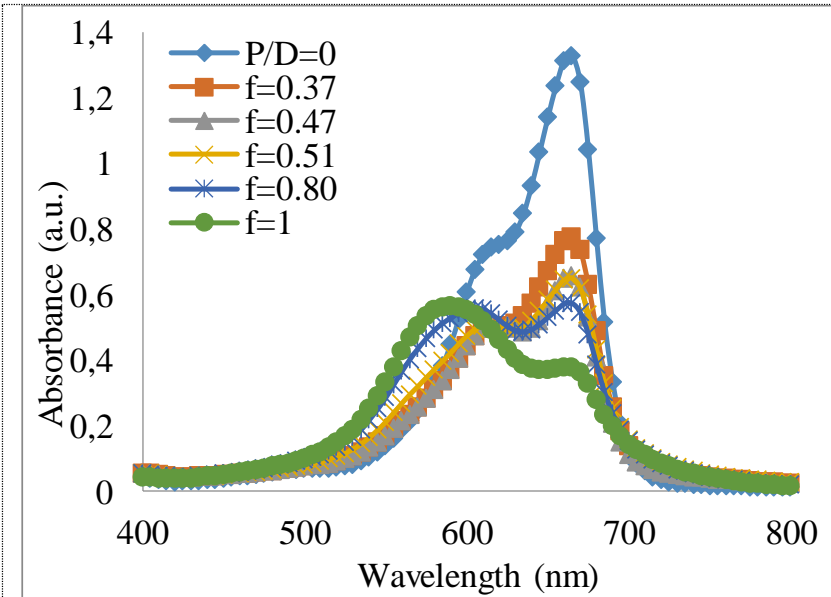

(a)

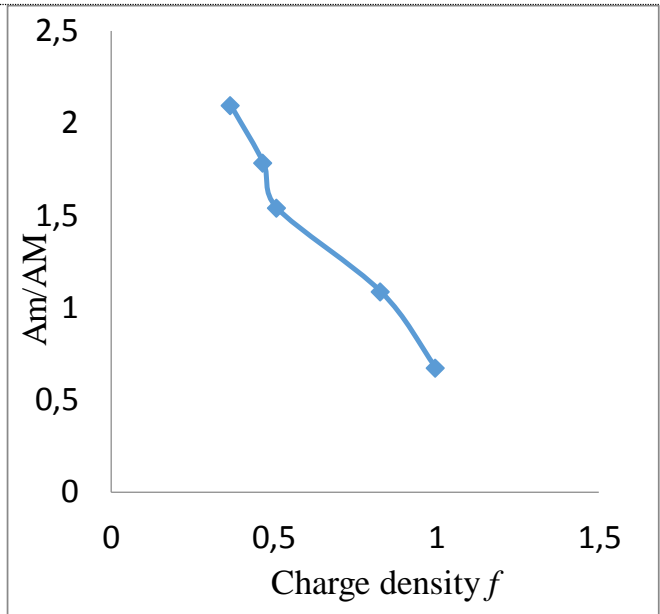

(b)

Figure 3. Absorption spectrum of dye in presence of PSSNa $(\mathrm{N}=2692)$ for different charge densities $f(a)$, evolution of the corresponding $\mathrm{A}_{\mathrm{m}} / \mathrm{A}_{\mathrm{M}}$ as a function of charge density $f(\mathrm{~b})$, at $\mathrm{P} / \mathrm{D}=1$.

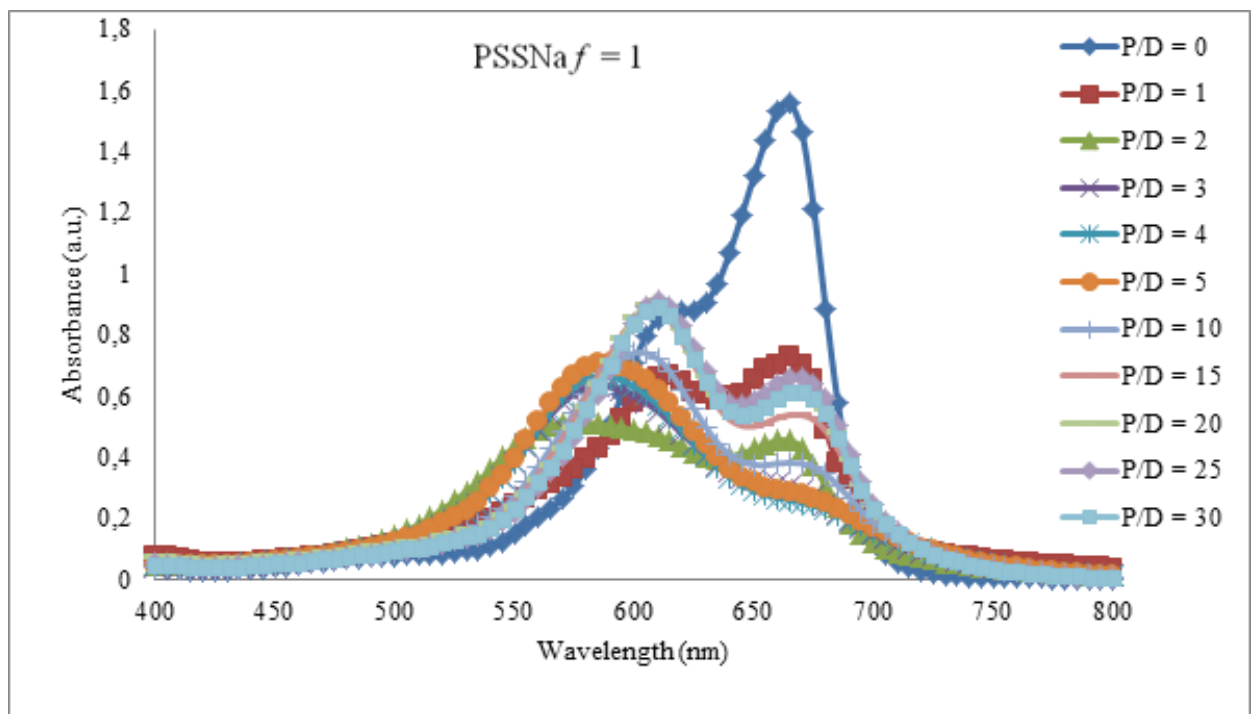

Figure 4. Absorption spectra of dye in presence of $\operatorname{PSSNa} f=1, \mathrm{~N}=2692$ at various $\mathrm{P} / \mathrm{D}$ ratios. 


\section{Effect of polyelectrolyte concentration}

Fig. 4 shows the evolution of the absorption spectra of the dye (MB) with the addition of increasing amounts of PSS $f=1, \mathrm{~N}=2692$. The addition of few amounts of PSSNa until P/D $=5$ causes the decrease of monomeric maximum absorption and the appearance of a new band around $590 \mathrm{~nm}$ (blue shift), indicating the formation of new metachromatic complexes between the cationic dye and the polyelectrolyte ${ }^{14,25-27}$. This behavior is similar to that found with the same dye "MB" with a non-aromatic polyelectrolyte which is polyacrylic acid ${ }^{14}$. At $\mathrm{P} / \mathrm{D}=10$, the metachromatic band shifts to higher wavelengths (red shift) and is now centered around $605 \mathrm{~nm}$, indicating a decrease of the metachromasy degree, concomitantly the intensity of the monomer band increases. At $15 \leq \mathrm{P} / \mathrm{D} \leq 25$, the metachromic band vanishes, the dimeric band reappears and its intensity remains constant, while the intensity of the monomeric band increases continually. This behavior indicates a release of the monomeric form and so a reversal of metachromasy due to the destabilization of the H-aggregate. At $\mathrm{P} / \mathrm{D}=30$, the intensity of the monomeric band decreases slightly again, while that of the dimer remains constant.

To determine the stoichiometry of PSSNa-MB complex using the ratio method, a plot of $A_{m} / A_{M}$ versus polyelectrolye $[\mathrm{P}] / \mathrm{Dye}[\mathrm{D}]$ ratios is presented on Fig.5. It emerges that the ratio $A_{m} / A_{M}$ decreases until a minimum value of $P / D$, then increases again. The stoichiometry of the complex is found to be $4: 1$, which indicates that binding takes place on one every four anionic sites ${ }^{13}$. This behavior is different from that observed for the same $\mathrm{MB}$ dye with polyacrylic acid ${ }^{14}$, for which the ratio $A_{m} / A_{M}$ decreases until $\mathrm{P} / \mathrm{D}=2$ i.e. the stoichiometry was found to be $2: 1$ indicating a binding of the dye every two anionic sites ${ }^{14,18}$. For higher $P / D$ values, the $A_{m} / A_{M}$ ratio increases smoothly in agreement with metachromasy reversal. This behavior is different from that of the same dye $\mathrm{MB}$ with polyacrylic acid for which the $A_{m} / A_{M}$ ratio remains constant when $P / D>2{ }^{14}$. The increase of the stoichiometry when passing from polyacrylic acid to polystyrene sulfonate indicates less overcrowding of the bound dyes on the PSSNa chain, because of PSSNa aromatic rings steric effects, although its electrostatic charge $f$ is higher. Moreover, the increase of the stoichiometry for PSSNa leads to more dye-dye aggregation.

The increase of the $A_{m} / A_{M}$ beyond the minimum value of $\mathrm{P} / \mathrm{D}$ in the present case, can be attributed to the presence of a high excess of polyelectrolyte, the polymer ion pairs formed by the polyanion and the cationic dye, are far from each other and do not aggregate, inhibiting then the cooperative selfbinding tendency of the counterions (dye), as if the polyelectrolyte shows a certain dispersant ability ${ }^{18}$. This behavior occurs unlike the case of other polyelectrolytes ${ }^{14}$, because PSSNa contains aromatic rings that undergo aromatic-aromatic interactions short-range with aromatic counterions (dye). So, the interaction between the anionic polyelectrolyte and the cationic dye is not only of electrostatic nature but also of hydrophobic nature.

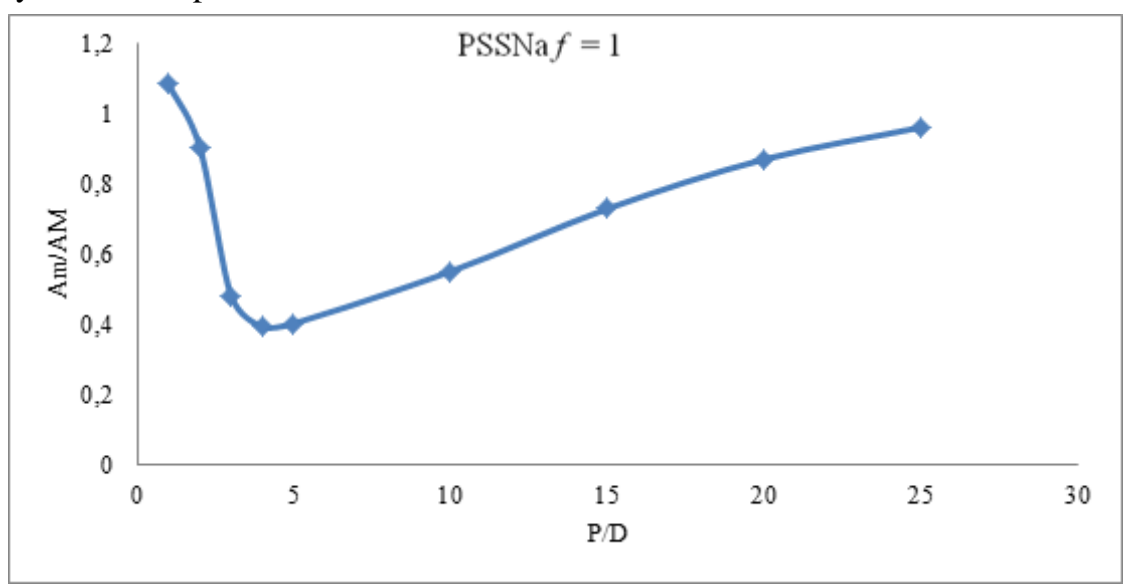

Figure 5. Stoichiometry for $\operatorname{PSSNa}(f=1, \mathrm{~N}=2692)$-MB complexes.

\section{Effect of added salt}

The effect of salt on self-association of ionic dyes in aqueous solution has been already investigated $^{31}$, and it was shown that the addition of $\mathrm{NaCl}$ salt enhances the dye-dye self-aggregation because of the increase of the ionic strength that considerably screens out the electrostatic interactions. On the other hand, the salt addition can also affect, by the same way, the polyelectrolyte conformation leading to an evolution from an extended to a collapsed conformation ${ }^{32}$. It was shown experimentally that the addition of sufficient amount of inorganic salt $(\mathrm{NaCl})$ on dye/polyelectrolyte systems including polyacrylic acid-MB ${ }^{14}$, causes ametachromasy reverse and a destruction of the aggregates ${ }^{14-16}$. 


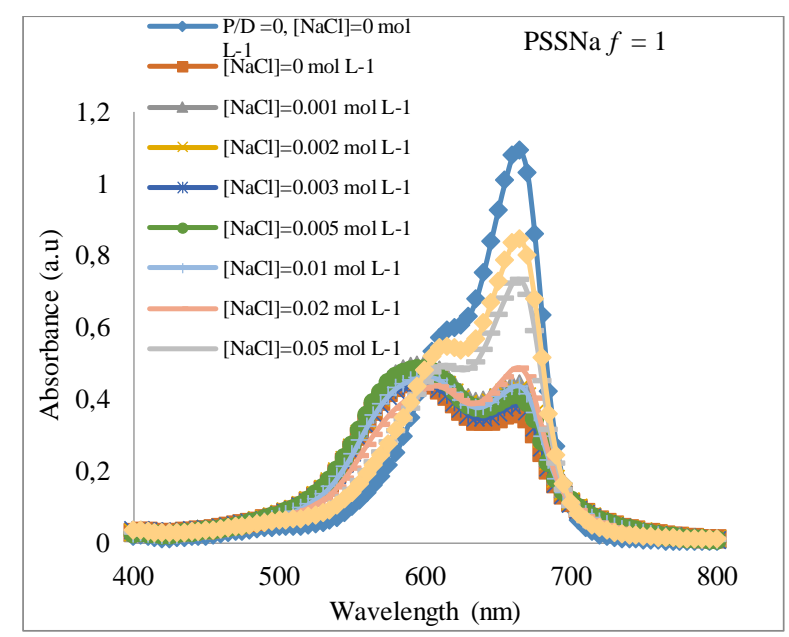

(a)

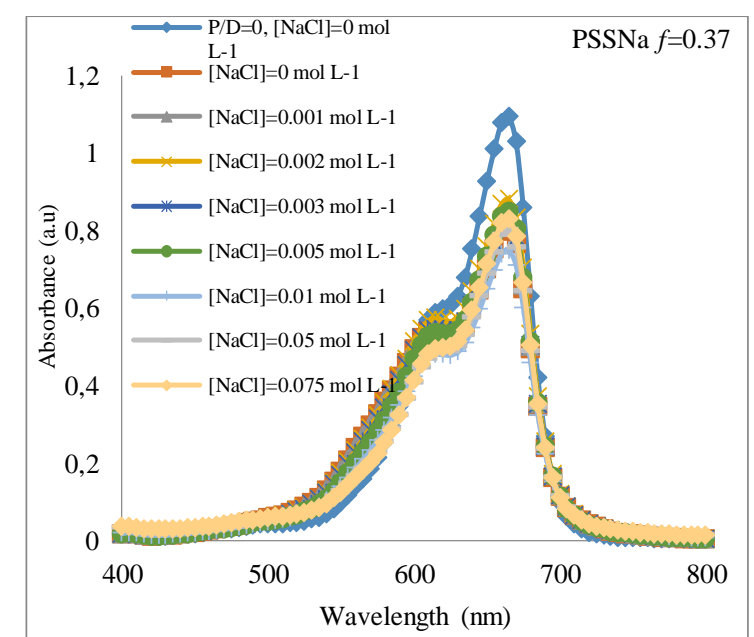

(b)

Figure 6. Absorbance variation spectrum of dye in presence of PSSNa, $\mathrm{N}=2692, f=1$ (a) and $f=0.37$ (b) as a function of added $\mathrm{NaCl}$ salt, at $\mathrm{P} / \mathrm{D}=1$.

Fig. 6 shows the evolution of the absorbance spectra of the MB dye in presence of $\operatorname{PSSNa} f=1$ (a) and $f=0.37$ (b) at $\mathrm{P} / \mathrm{D}=1$ and $\mathrm{N}=2692$, as a function of $\mathrm{NaCl}$ salt addition in a concentration range $\mathrm{c}_{\mathrm{s}}$ between 0 and $7.510^{-2} \mathrm{~mol} \mathrm{\textrm {L } ^ { - 1 }}$. It emerges that for $\operatorname{PSSNa} f=1$ and as salt concentration $\mathrm{c}_{\mathrm{s}}$ increases, the monomer band remains constant while the metachromasy band increases, until $\mathrm{c}_{\mathrm{s}} \approx 5.10^{-3}$ mol L ${ }^{-1}$. From $\mathrm{c}_{\mathrm{s}}=10^{-2} \mathrm{~mol} \mathrm{~L}^{-1}$, the monomer band increases again while the metachromatic band intensity decreases. Ultimately, this behavior is in agreement with a reverse of metachromasy. However, for PSSNa $f=0.37$, the absorbance spectra reveal that the monomeric and dimeric bands are not very sensitive to salt addition. For $\mathrm{P} / \mathrm{D}=5$, the evolution of the absorbance spectra for both PSSNa $f=1$ and $f=0.37$ (not shown in Fig.7), are very similar to Figure $6 \mathrm{a}(\operatorname{PSS} f=1, \mathrm{P} / \mathrm{D}=1)$. Indeed, they show the presence of metachromatic band in absence of salt, that remains unchanged until $\mathrm{NaCl}$ concentration of $2.10^{-2} \mathrm{~mol} \mathrm{~L}^{-1}$ for PSS $f=0.37$ and $5.10^{-2} \mathrm{~mol} \mathrm{~L}^{-1}$ for PSSNa $f=1$. Thus, the metachromatic band disappears, the dimeric band appears and remains constant while the original monomeric band increases and is gradually restored for both PSSNa. This behavior indicates the destruction of the dye aggregates. Note that for the case of polyacrylic acid-MB complex ${ }^{14}$, the salt concentration needed to reverse metachromasy was $10^{-2} \mathrm{~mol} \mathrm{~L}^{-1}$ at $\mathrm{P} / \mathrm{D}=20$, which should correspond approximately to a concentration of $10^{-2} / 4 \mathrm{~mol} \mathrm{~L} \mathrm{~L}^{-1}$ if we deal with a ratio of $\mathrm{P} / \mathrm{D}=5$. So in the latter case of polyacrylic acid ${ }^{14}$, the metachromasy reverse occurs at much lower salt concentrations than in the former case. This behavior shows that the rapid decrease of metachromatic complex stability with added $\mathrm{NaCl}$ salt is a typical behavior of systems where only long-range electrostatic interaction between dye and polyelectrolyte is the main force ${ }^{14}$. However, in the case of low dependence of the interaction with the ionic strength ${ }^{18}$ such as the case of polyelectrolytes having aromatic groups directly attached to the negatively charged groups (for example polystyrene sulfonate), there are other interactions namely aromatic-aromatic interactions acting at short range, in addition to the electrostatic interactions. These aromatic-aromatic interactions are so resistant to the cleaving effect of added salt and make the metachromatic complex more stable.

The effect of $\mathrm{NaCl}$ on reversal metachromasy on PSSNa-MB complex is displayed by the plot of $\mathrm{A}_{\mathrm{m}} / \mathrm{A}_{\mathrm{M}}$ versus $\mathrm{NaCl}$ concentration on Fig. 7, for $\mathrm{PSSNa}$ at $\mathrm{P} / \mathrm{D}=1$ and $\mathrm{P} / \mathrm{D}=5$. For $\mathrm{P} / \mathrm{D}=1$, the $\mathrm{A}_{\mathrm{m}} / \mathrm{A}_{\mathrm{M}}$ for $\operatorname{PSS} f=0.37$ is higher than that of PSSNa $f=1$ whatever is the salt concentration, because the dye is already unaggregated in the former case. For $\operatorname{PSSNa} f=1, \mathrm{~A}_{\mathrm{m}} / \mathrm{A}_{\mathrm{M}}$ remains constant until $\mathrm{c}_{\mathrm{s}} \approx 5$ $10^{-3} \mathrm{~mol} \mathrm{~L} \mathrm{~L}^{-1}$ and at higher $\mathrm{c}_{\mathrm{s}}$, the ratio $\mathrm{A}_{\mathrm{m}} / \mathrm{A}_{\mathrm{M}}$ increases indicating a destruction of the MB-PSSNa $f=1$ complex, then it becomes constant. At $\mathrm{P} / \mathrm{D}=5$ and $0 \mathrm{~mol} \mathrm{~L}{ }^{-1} \mathrm{NaCl}, \mathrm{A}_{\mathrm{m}} / \mathrm{A}_{\mathrm{M}}$ for $\mathrm{PSSNa} f=0.37$ is slightly higher than that for $f=1$, but as $\mathrm{c}_{\mathrm{s}}$ increases the evolution of the two ratios becomes close to each other's showing a similar behavior, as described previously and showing that the effect of charge density $f$ is well screened when sufficient amount of salt is added to the polyelectrolyte/dye solutions. 


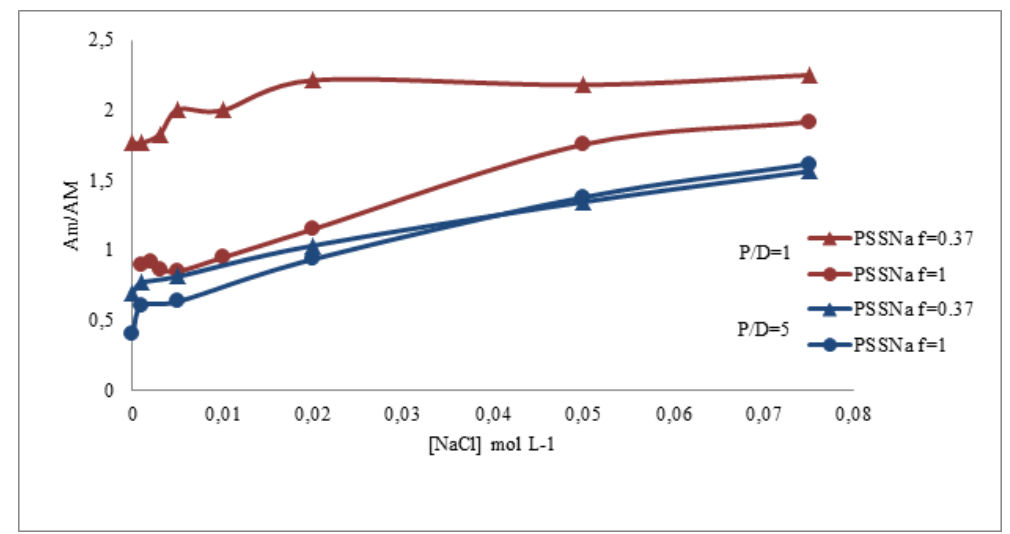

Figure 7. Effect of added $\mathrm{NaCl}$ on reversal metachromasy for $\mathrm{PSSNa}(\mathrm{N}=2692, f=1$ and $f=0.37)-\mathrm{MB}$ complexes, at $\mathrm{P} / \mathrm{D}=1$ and $\mathrm{P} / \mathrm{D}=5$.

\section{Effect of added tetrahydrofuran "THF"}

The metachromatic effect results on the bound dye molecules to polyelectrolyte becoming close enough to form polymeric aggregates, extended at large scale. It was already established that alcohol and urea destroy the metachromatic complexes between dye and polyelectrolytes ${ }^{13}$. This evolution suggests that the hydrophobic interactions are involved in the induction of metachromasy and any external parameter that can weaken the hydrophobic interactions between the stacked dye molecules forming the metachromatic complex with polyelectrolyte, contribute to the decrease of the metachromasy degree and can evolve until its destruction.

Note that the addition of THF results in a decrease of the dielectric constant $\varepsilon$ of the medium (water/THF) ${ }^{33}$, it decreases from $\varepsilon=78.50$ at $0 \%$ THF (pure water) to $\varepsilon=45.85$ at $35 \%$ THF- $65 \%$ water ${ }^{33}$. It should lead to a reduction of the dissociation of the ion pairs along the polyelectrolyte chain ${ }^{34}$ and therefore a decrease in the interaction between the polyelectrolyte and the dye.

The dye absorption in presence of PSSNa $(\mathrm{N}=2692, f=1$ at $\mathrm{P} / \mathrm{D}=5)$ aqueous solutions as a function of THF addition is presented in Fig. 8. It emerges that as THF increases, the metachromatic band shifts to higher wavelengths and its intensity decreases and that corresponding to the monomer increases however, slightly. From an addition of $17 \%$ of THF in the solvent mixture, the metachromic band is completely disturbed and shifted from 590 $\mathrm{nm}$ to $610 \mathrm{~nm}$, while the dimeric band observed previously in pure water appears again and its intensity increases, as well as the intensity of the monomer band. Indeed, the latter increases considerably and reaches that of dye in pure water dealing with complete reversal of metachromasy. So, the absorption spectra of the dye evolve under THF addition and become similar to that of dye in pure water. Moreover, beyond sufficient amount of added THF, the intensity of the dimeric form becomes constant and lower to that of dye in pure water, while that of the monomer form at the expense becomes high and close to that of dye in pure water. THF addition causes reversal of metachromasy and predominance of the monomer format the expense of the dimeric form in comparison to the case in pure water. The same evolution was observed with PSSNa $f=0.37, \mathrm{P} / \mathrm{D}=5$ (data not shown here), namely the metachromatic band disappears at $12 \%$ of added THF, the dimeric and monomer bands reappear and their intensity increases. This behaviour is similar to that observed when urea or alcohols were added to cationic dyes including $\mathrm{MB}{ }^{35}$, complexed with anionic polyelectrolytes ${ }^{30,13,36}$.

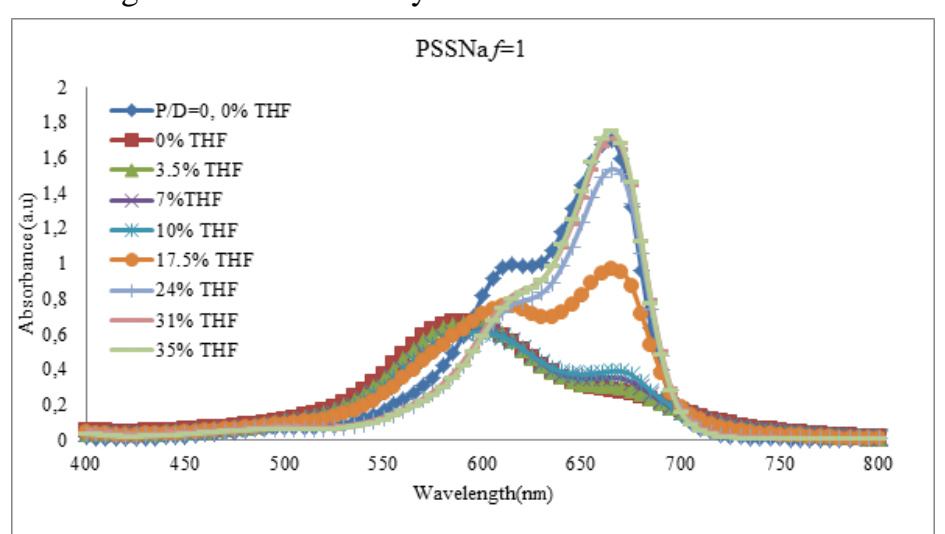

Figure 8. Absorbance variation spectrum of dye in presence of PSSNa $(\mathrm{N}=2692, f=1)$ as a function of THF addition, at $\mathrm{P} / \mathrm{D}=5$. 
The dye is released as THF amount increases and the ratio $\mathrm{A}_{\mathrm{m}} / \mathrm{A}_{\mathrm{M}}$ for PSSNa $f=1$ increases from a low value about 0.4 to reach a high value of 1.65 (Fig. 9). For PSSNa $f=0.37$, the ratio $\mathrm{A}_{m} / \mathrm{A}_{M}$ starts from a higher value about 0.70 and increases faster than for $f=1$ (Fig. 9), in agreement with a faster release of the dye initially at the aggregated state, in case of PSSNa $f=0.37$, as a function of THF addition.

One can also note that THF addition causes a conformation transition from a collapsed conformation to a stretched one for PSSNa $f=0.37$, however for the fully charged PSSNa $f=1$, THF addition is not accompanied by transition conformation ${ }^{37}$ and this difference may also affect the release of the dye from the two polyelectrolytes, being faster for PSSNa $f=0.37$.

The $\%$ of THF to reverse metachromasy in case of PSSNa $f=1$ is higher than that needed in case of $\operatorname{PSSNa} f=0.37$. So, this indicates that $\operatorname{PSSNa} f=1$ $\mathrm{MB}$ complex is more stable than PSSNa $f=0.37-\mathrm{MB}$ complex, with the involvement of hydrophobic interactions sensitive to THF addition, existing either between dye molecules or dye/polyelectrolyte in our case. The higher stability of PSSNa $f=1$ against $\operatorname{PSSNa} f=0.37$ can be explained fundamentally by the higher electrostatic charge in case of fully charged PSSNa and so the higher attractive electrostatic interactions between the dye and this polyelectrolyte $(f=1)$.

Moreover and on the basis of these results, the effect of THF addition induce the destruction of structured regions around the dye ions and the association of methylene blue to form aggregates is less favorable because there is less entropy to be gained. Thus solvent nature induced hydrophobic interaction seems to play an important part in the association of dyes, and presumably other aromatic type molecules.

From point of view application, we can conclude that polyelectrolyte is active as flocculent when the effluent is free of organic solvent.

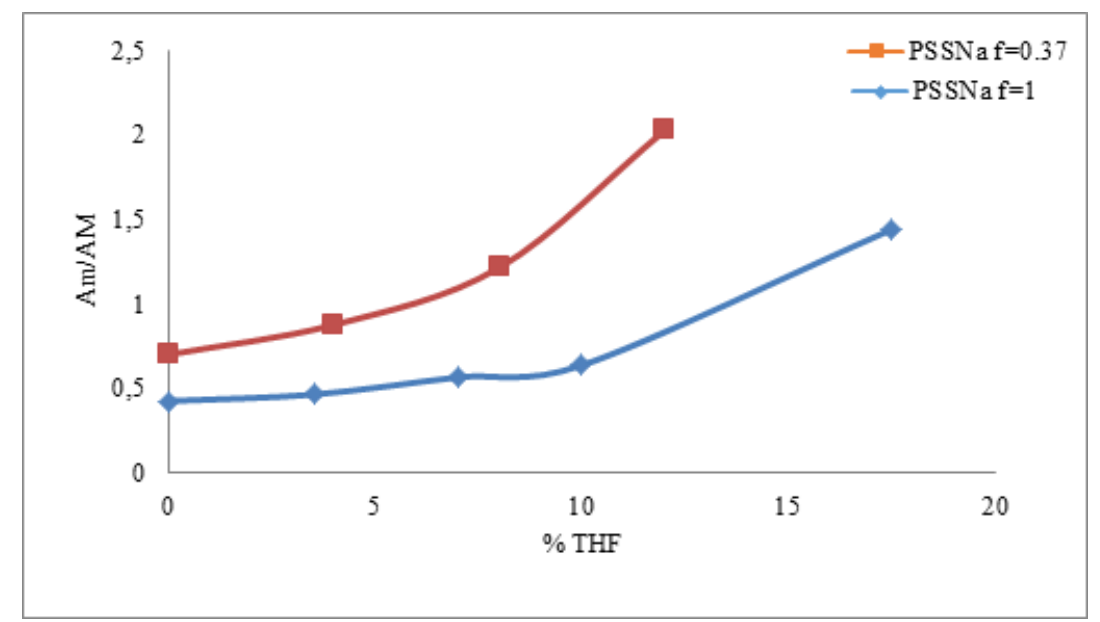

Figure 9. Effect of THF addition on reversal metachromasy in $\operatorname{PSSNa}(\mathrm{N}=2692, f=1$ and $f=0.37)-\mathrm{MB}$ complexes, at $\mathrm{P} / \mathrm{D}=5$.

\section{Effect of THF Treatment}

Here we are interested to investigate the effect of THF treatment that can reflect real situation that some effluents can undergo.

In what follows, we note "\% THF" the percentage by volume of THF used initially in the solvent mixture before its evaporation and substitution with water.

Fig. 10a shows the evolution of the absorption spectra of the dye (MB) in $\operatorname{PSSNa}(f=1, \mathrm{P} / \mathrm{D}=5)$ aqueous solutions, as a function of THF treatment from different solvent mixtures of $\mathrm{H}_{2} \mathrm{O} / \mathrm{THF}$. It emerges that after evaporation of THF and its completely replacement with $\mathrm{H}_{2} \mathrm{O}$, the original metachromatic band is restored and appears at the same wavelength, while its intensity evolves slightly with THF treatment and for $35 \%$ THF treatment, it just overlaps the curve corresponding to that without treatment. It is worth noting that THF treatment does not affect the electrostatic interactions on PSSNa aqueous solutions as already revealed in our previous study by small angle scattering experiments ${ }^{38}$. This behaviour indicates that the previous released monomer dye upon THF addition reaggregates again and regains its original environment and structure after THF treatment, as the same that polyelectrolyte/dye solution without treatment. As a consequence, the ratio $A_{m} / A_{M}$ remains substantially constant with THF treatment (Fig. 10b). So, this treatment can be regarded as reversible despite the strong action of the previously added THF and according to our knowledge, this behaviour is highlighted for the first time on such dye based systems. 


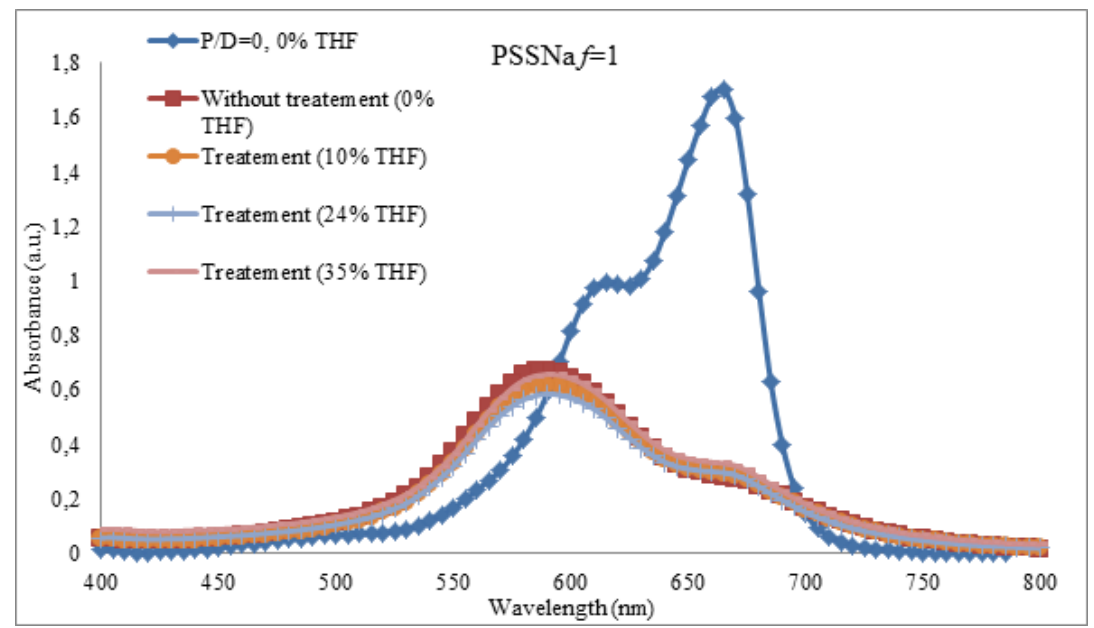

(a)

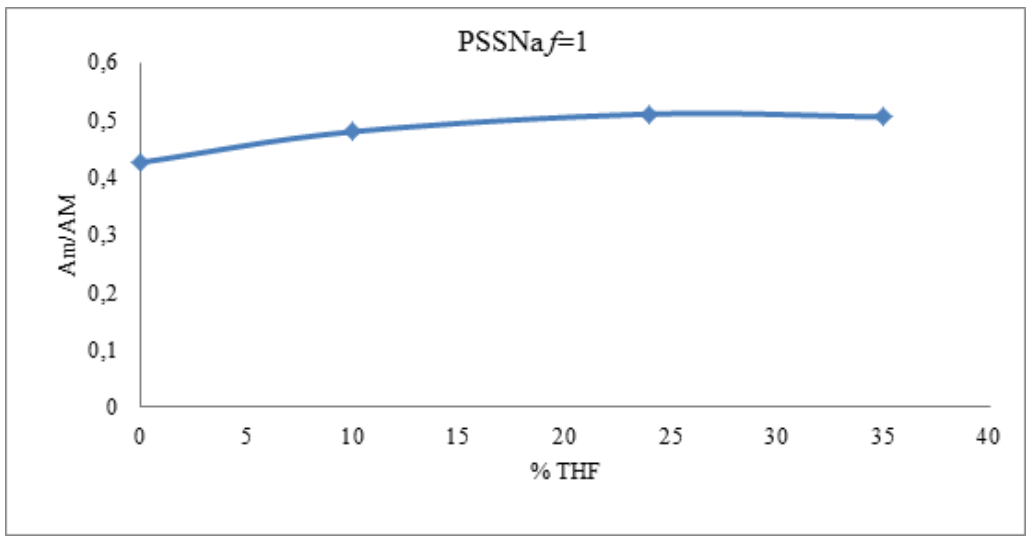

(b)

Figure 10. Absorption spectra of dye in presence of $\operatorname{PSSNa}(f=1, \mathrm{~N}=2692, \mathrm{P} / \mathrm{D}=5)$ as a function of THF treatment (a), the evolution of $A_{m} / A_{M}$ ratio with THF treatment (b).

\section{Determination of interaction parameters}

The interaction constant $\mathrm{K}_{\mathrm{c}}$ for the complex formation between PSSNa and MB was determined by absorbance measurements at the metachromatic bands at different temperatures taking different set of solutions differing only by their polyelectrolyte concentration, the dye concentration is kept constant. The results were treated using Rose-Drago ${ }^{39}$ equation:

$\frac{C_{D} C_{P}}{A-A_{0}}=\frac{1}{K_{C} L\left(\varepsilon_{D P}-\varepsilon_{D}\right)}+\frac{C_{P}}{L\left(\varepsilon_{D P}-\varepsilon_{D}\right)}$
A refers to the absorbance of the complex measured at $590 \mathrm{~nm}, \mathrm{~A}_{0}$ is the absorbance of the pure dye MB at $590 \mathrm{~nm}, \mathrm{c}_{\mathrm{P}}$ is the polyelectrolyte solution concentration, $c_{D}$ is the dye concentration, $\mathrm{L}$ is the optical path length of the solution, $\varepsilon_{\mathrm{D}}$ and $\varepsilon_{\mathrm{DP}}$ are the respective molar extinction of the dye and the dye bound to polymer, $\mathrm{K}_{\mathrm{c}}$ is the binding constant. The value of binding constant $\mathrm{K}_{\mathrm{c}}$ was then obtained from the slope and intercept of the plot of $\mathrm{c}_{\mathrm{D}} \cdot \mathrm{c}_{\mathrm{P}} /\left(\mathrm{A}-\mathrm{A}_{0}\right)$ against $\mathrm{c}_{\mathrm{P}}$ as shown on Fig. 11, for both PSSNa $f=1$ and $f=0.37$. 


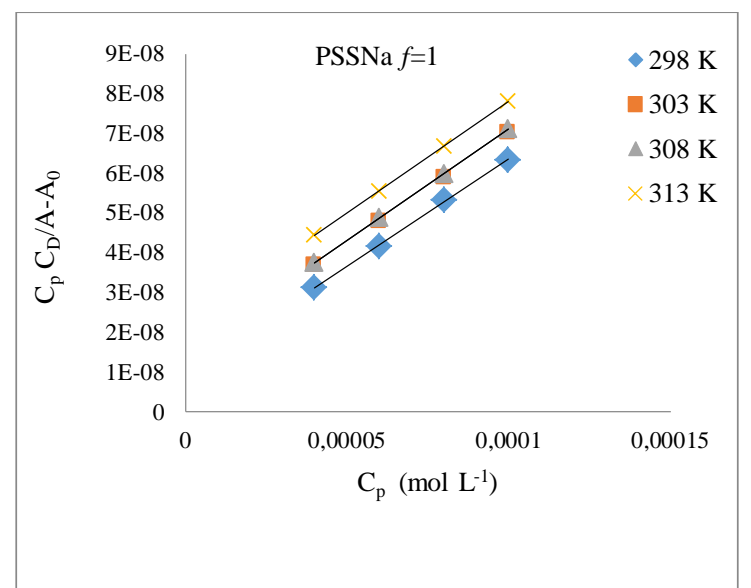

(a)

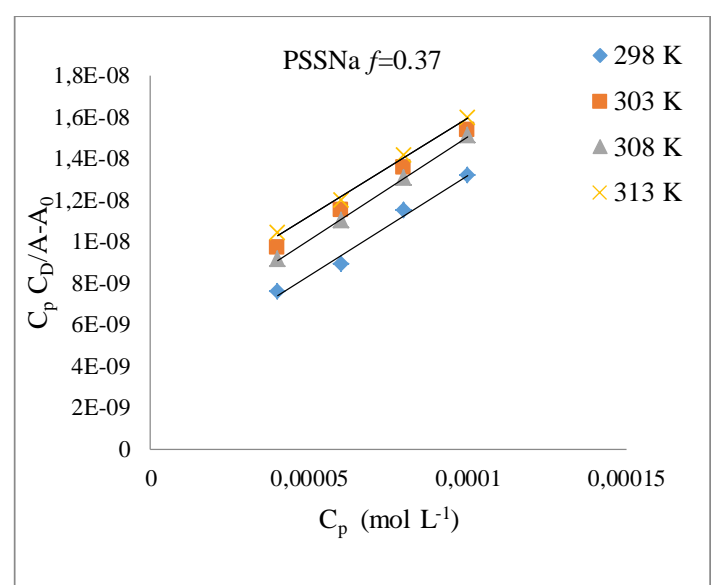

(b)

Figure 11: Plots of $\mathrm{c}_{\mathrm{D}} \cdot \mathrm{c}_{\mathrm{P}} /\left(\mathrm{A}-\mathrm{A}_{0}\right)$ as a function of $\mathrm{c}_{\mathrm{P}}$, for PSSNa $f=1$ (a) and PSSNa $f=0.37$ (b).

The extracted values of $\mathrm{K}_{\mathrm{c}}$ are given in Table 1 . It emerges that as the temperature increases, the value of the binding constant decreases for both PSS $f=1$ and $f=0.37$. So, the increase of temperature is unfavorable for the complex formation and the interaction between the polyelectrolytes and the dye, as already observed for other systems 14,15,13. Moreover, the binding constant $\mathrm{K}_{\mathrm{c}}$ is higher for the case of $\operatorname{PSSNa} f=1$ than for the case $f=0.37$, in agreement with a more stability of the $\operatorname{PSSNa} f=1$ MB complex than PSSNa $f=0.37-\mathrm{MB}$ complex and as a consequence electrostatic interaction plays the major role between PSSNa and MB.

One can also note that the binding constant $\mathrm{K}_{c}$ values found for PSSNa $f=1-\mathrm{MB}$ are higher than those found for the same dye MB with other polyelectrolytes, such the case of polyacrylic acid ${ }^{14}$, or even other dyes ${ }^{15}$, indicating that under suitable experimental conditions PSSNa is more effective than polyacrylic acid.

Thermodynamic parameters were calculated in order to elucidate the nature of interaction between dye and polyelectrolytes.

The Gibbs free energy $\Delta G$ is calculated from the equation below:

$\Delta \mathrm{G}=-\mathrm{RT} \ln \left(\mathrm{K}_{\mathrm{c}}\right)$

The enthalpy $\Delta \mathrm{H}$, was determined graphically by plotting $\ln \left(\mathrm{K}_{\mathrm{c}}\right)$ versus $1 / \mathrm{T}$, according to Van't Hoff equation (equation. 3), represented in Fig. 12. $\ln \left(\mathrm{K}_{\mathrm{c}}\right)=-\frac{\Delta \mathrm{H}}{\mathrm{RT}}+\mathrm{c}=-\frac{\Delta \mathrm{H}}{\mathrm{RT}}+\frac{\Delta \mathrm{S}}{\mathrm{R}} \quad$ (Van't Hoff equation)

According to equation. 4 below, linking $\Delta \mathrm{G}$ to $\mathrm{T}$ :

$\Delta \mathrm{G}=\Delta \mathrm{H}-\mathrm{T} \Delta \mathrm{S}$

$\Delta \mathrm{S}$ can be determined from the slope of the corresponding curve and the extracted values of $\Delta S$ are given in Table 1.

The negative values of $\Delta \mathrm{G}$ that increasing with temperature for both PSSNa complexes indicate that the complexation reaction is spontaneous (Table 1) and the negative value of $\Delta \mathrm{H}$ indicates that the reaction is exothermic. On the other hand, the negative entropy indicates more ordered state of the dye ions due to its aggregation than in pure water, supporting the aggregation theory of the dyepolymer complex formation during metachromasy ${ }^{40}$. This negative value $(\Delta S)$ means also that hydrophobic interactions suggesting less directed interactions than the electrostatics ones do not play a major role between the dye and the polyelectrolytes $41,30,14,15$. This result is different to what has been reported in ${ }^{18}$, suggesting that the hydrophobic aromatic-aromatic interactions may constitute the major forces driving the interaction of the polyelectrolytes (PSSNa $f=1$ ) with the dye ions rhodamine 6G. Consequently, the electrostatic interaction plays the major role in the formation of the PSSNa-MB complex in our case. 
Table 1. Thermodynamic parameters of interaction for PSSNa $(f=1)$-MB and PSSNa $(f=0.37)$-MB complexes

\begin{tabular}{|c|c|c|c|c|c|}
\hline & $\mathbf{T}(\mathbf{K})$ & $\begin{array}{c}\mathbf{K}_{\mathrm{c}} \\
\left.\left(\mathbf{d m}^{3} \mathrm{~mol} \mathrm{~L}\right)^{-1}\right)\end{array}$ & $\Delta G\left(\mathrm{KJ} \mathrm{mol}^{-1}\right)$ & $\Delta \mathrm{H}\left(\mathrm{KJ} \mathrm{mol}^{-1}\right)$ & $\begin{array}{c}\Delta S \\
\left(\mathrm{KJ} \mathrm{mol}^{-1} \mathbf{K}^{-1}\right)\end{array}$ \\
\hline \multirow{4}{*}{$\operatorname{PSSNa} f=1$} & 298 & 60.458 & -27.278 & \multirow{4}{*}{-41.281} & \multirow{4}{*}{-0.0475} \\
\hline & 303 & 37.440 & -26.529 & & \\
\hline & 308 & 36.169 & -26.878 & & \\
\hline & 313 & 25.212 & -26.375 & & \\
\hline \multirow{4}{*}{$\operatorname{PSSNa} f=0.37$} & 298 & 27.798 & -25.353 & \multirow{4}{*}{-30.630} & \multirow{4}{*}{-0.0183} \\
\hline & 303 & 18.710 & -24.781 & & \\
\hline & 308 & 16.774 & -24.911 & & \\
\hline & 313 & 14.968 & -25.018 & & \\
\hline
\end{tabular}

The uncertainty limits of $\mathrm{K}_{\mathrm{c}}$ and $\Delta \mathrm{G}$ values are $\pm 2 \%$ and $\pm 3 \%$ respectively.

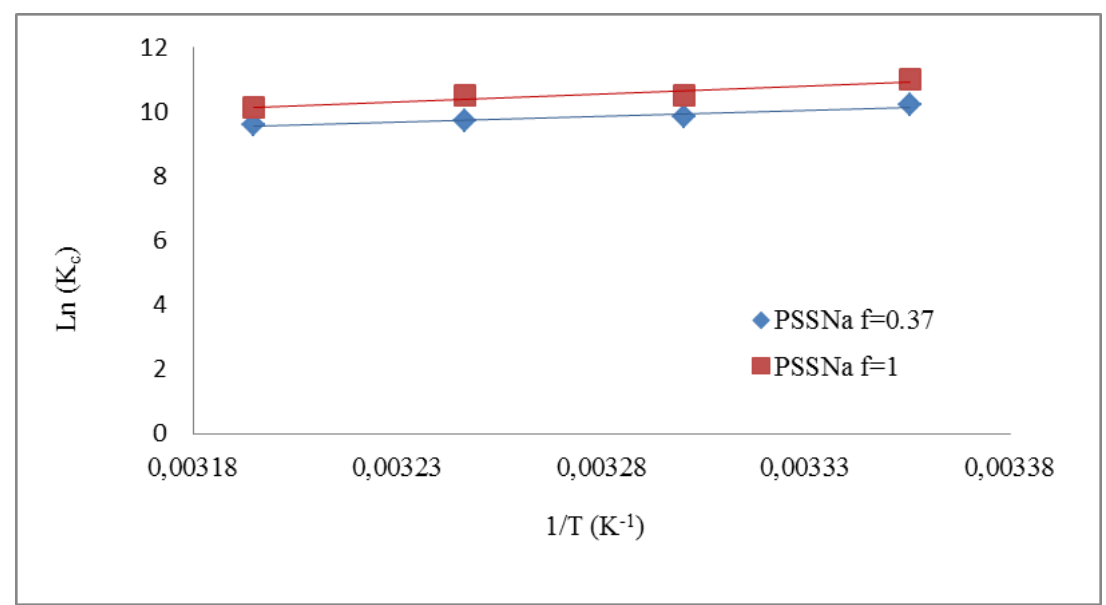

Figure 12. Van’t Hoff plot for PSSNa-MB complexes.

\section{Conclusion}

The polyelectrolyte poly-(sodium styrene sulfonate $)_{f}$-co-(styrene) $)_{1-f}$ is effective to induce metachromasy in the MB dye, as $\mathrm{H}$-aggregates. The optimal chain lengths enhancing metachromsy for PSS $f=1$ range from $20700 \mathrm{~g} \mathrm{~mol}^{-1}$ and $554.550 \mathrm{~g}$ $\mathrm{mol}^{-1}$. On the other hand, as the electrostatic charge density $f$ increases the interaction PSSNa-MB is more favored, meaning that the fully charged PSSNa $(f=1)$ is the optimal polyelectrolyte for PSSNa-MB aggregation. Moreover, the binding constant $\mathrm{K}_{\mathrm{c}}$ is higher for the fully charged PSSNa $f=1$ than for $f=0.37$, in agreement with a more stable complex for the fully charged PSSNa $f=1$. This result implies that in practice, it is more advantageous to use the fully charged $\operatorname{PSSNa} f=1$ inducing greater degree of metachromasy than PSSNa $f=0.37$, at the same polyelectrolyte concentration.

The addition of sodium chloride salt, induced changes in the spectra showing clearly the gradual destabilization of PSSNa-MB complex causing its reversal of metachromasy only at sufficient amounts of salt, because of the presence of short range aromatic/aromatic interactions between dye and polyelectrolyte. This behavior is the signature that the interactions between MB and PSSNa are also of electrostatic nature. Also, the addition of THF causes a reversal of metachromasy of PSSNa-MB complexes. On the other hand, the destabilization of the PSSNa $f=0.37-\mathrm{MB}$ complex is faster than in the case of the fully charged/MB complex, in agreement with a more stable complex in the latter case. Finally, the "THF treatment", investigated for the first time for Polyelectrolyte-Dye systems shows a full reversibility of this system with this action.

As an extension of this work, it will be interesting to investigate the interactions of $\mathrm{MB}$ with other highly charged quenched polyelectrolytes that not bear aromatic ring, in order to assess the electrostatic component versus the hydrophobic one in that kind of systems and it will be the purpose of a forthcoming paper. 


\section{Acknowledgements}

The authors acknowledge the Tunisian Ministry of Higher Education for its financial support through a $\mathrm{Ph}$.D. research grant for S.BM.

\section{References}

1- G. Bayramoglu, M. Y. Arica, Adsorption kinetics and thermodynamic parameters of cationic dyes from aqueous solutions by using a new strong cation-exchange resin, J .Hazard. Mater, 2007, 143, 135-143.

2- T. Robinson, G. McMullan, R. Marchant and P. Nigam, Remediation of dyes in textile effluent: a critical review on current treatment technologies with a proposed alternative, Bioresour. Technol, 2001, 77, 247-255.

3- E.S. Dragan and I.A. Dinu, Interaction of disazo dyes with quaternized poly(dimethylaminoethyl methacrylate) as a function of the dye structure and polycation charge density, J. Appl. Polym. Sci. 2009, 112, 728-735.

4- L. D'ilario, I. Francolini, A. Martinelli and A. Piozzi, Some insight on the HeparinToluidine Blue interaction, Dyes. Pigm, 2009, 80, 343-348.

5- E.G. Mamchits, I.R. Nasimova, E.E. Makhaeva and A.R. Khokhlov, Effect of polyelectrolytes on aggregation of a cyanine dye, Poly. Sci, 2006, 48, 91-96.

6- S.S. Carrasco, J.G. Delcros, A.A.M. García, F.S. Jiménez and F.J. Ramírez, Study by optical spectroscopy and molecular dynamics of the interaction of acridine-spermine conjugate with DNA Biophys, Chem, 2008, 133, 54-65.

7- Y.Z. Zhang, X. Xiang, P. Mei, J. Dai and L.L. Zhang, Spectroscopic studies on the interaction of Congo Red with bovine serum albumin, Spectrochim. Acta A, 2009, 72, 907-914.

8- K. Yurekli, E. Conley and R. Krishnamoorti, Effect of laponite and a nonionic polymer on the absorption character of cationic dye solutions, Langmuir, 2005, 21, 5825-5830.

9- G. R. Rose and M. R. John, Encyclopedia of Polymer Science and Engineering, Wiley: New York, 1987, 7, 211-233.

10- E. S. Dragan, L. Ghimici, In Focus on Ionic Polymers; Dragan, E. S., Ed.; Research Signpost: Kerala, India 2005, 223-259.

11- B. Bolto and J. Gregory, Review: Organic polyelectrolytes in water treatment, Water. Res. 2007, 41, 2301-2324.

12- C. Peyratout, E. Donath and L. Daehne, Electrostatic interactions of cationic dyes with negatively charged polyelectrolytes in aqueous solution, J. Photochem. Photobiol. A: Chemistry 2001, 142, 51-57.

13- R. Nandini, B. Vishalakshi, A study of interaction of cationic dyes with anionic polyelectrolytes, Spectrochimica. Acta. Part A., 2010, 75, 14-20.

14- A. Ben Fradja, and A. Hafiane et al, Effect of chemical parameters on the interaction between cationic dyes and poly(acrylic acid), J.

Photochem. Photobiol. A: Chemistry, 2014, 284, 49-54.

15- A. Ben Fradj, A. Hafiane, et al, Spectrophotometric study of the interaction of toluidine blue with poly(ammonium acrylate), J. Mol. Liq, 2014, 194, 110-114.

16- A. Ben Fradj, A. Hafiane et al, Investigation on the interaction of Safranin $\mathrm{T}$ with anionic polyelectrolytes by spectrophotometric method Spectrochim Acta A Mol Biomol Spectrosc, 2014, 131, 169-176.

17- S. Gadde, E.K. Batchelor and A.E. Kaifer, the formation of cyanine dye $\mathrm{H}$ - and J-aggregates with cucurbituril hosts in the presence of anionic polyelectrolytes, J. Chem. Eur. 2009, 15, 6025-6031.

18- I. M Villoslada, et al,H. Nishide, Comparative study of the self-aggregation of rhodamine $6 \mathrm{G}$ in the presence of poly(sodium 4styrenesulfonate),poly(N-phenylmaleimide-coacrylic acid), poly(styrene-alt-maleic acid), andpoly(sodium acrylate), J. Phys. Chem. B, 2010, 114, 11983-11992.

19- M. Kasha, H.R. Rawls and M.A. El-Bayoumi, The exciton model in molecular spec-troscopy, Pure Appl. Chem. 1965, 11, 371-392.

20- H. Yao, T. Isohashi, K. Kimura, Electrolyteinduced mesoscopic aggregation of thiacarbocyanine dye in aqueous solution: counterion size specificity, J. Phys.Chem. B, 2007, 111, 7176-7183.

21- B. Boruah, P.M. Saika and R.K. Dutta, Spectrophotometric of the monomerdimerprocess of C.I. Basic Blue 9 in aqueous polymer-surfactant system, Dyes. Pigm, 2010, 85, 16-20.

22- H. S Makowski, R. D Lundberg, G. S. Singhal Flexible polymeric compositions comprising a normally plastic polymer sulfonated to about 0.2 to about 10 mole \% sulfonate. U.S Patent 3870841, 1975 to Exxon Research and Engineering Company.

23- W. Essafi, F. Lafuma and C. E. Williams, in Macro-ion Characterization. From Dilute solutions to complex fluids, K.S. Schmitz, ed., ACS Symposium Series. 1994, 548, 278-286.

24- D. Baigl, T. A. P. Seery and C. E. Williams, On the pearl size of hydrophobic polyeletrolytes, Macromolecules, 2002, 35, 2318-2326. 
25- M.K. Pal and S. Basu,. Polyelectrolyte chromotropes in metachromacy, Makromol.Chem, 1958, 27, 69-79.

26- P. Mukerjee, A.K. Ghosh, P. Mukerjee and A.K. Ghosh, effect of urea on methy-lene blue, its self-association, and interaction with polyelectrolytes in aqueous solution, J. Phys. Chem, 1963, 67,193-197.

27- S. Dragan, L. Ghimici, M. Cristea and A. Airinei, Polyelectrolyte complexes. III. Binding characteristics of some polydentate anionic azo dyes to polycations with N,N-dimethyl-2hydroxypropylene ammonium chloride units in the mainchain, Acta. Polym, 1999, 50, 260-266.

28- F.C. Spano and S. Siddiqui, Excitonvibrational coupling in pinwheel aggregates of conjugated molecules, Chem. Phys. Lett. 1999, 314, 481-487.

29- W. Essafi, F. Lafuma, D. Baigl and C. E. Williams, Anomalous counterion condensation in salt-free hydrophobic polyelectrolyte solutions: Osmotic pressure measurements, Europhys. Lett., 2005, 71, 938-944.

30- R. Nandini and B. Vishalakshi, A comparative study of polyelectrolyte-dye interactions Spectrochimica. Acta. Part A, 2009, 74, 1025-1030.

31- J. Xiang, X. Yang, C. Chen, Y. Tang, W. Yan and $\mathrm{G}$. Xu, Effects of $\mathrm{NaCl}$ on the $\mathrm{J}$ aggregation of two thiacarbocyanine dyes in aqueous solutions, J. Colloid. Interface Sci, 2003, 258 198-205.

32- M. Nierlich, P. G de Gennes et al, Small angle neutron scattering by semi-dilute solutions of polyelectrolyte, J. Physique, 1979, 40, 701-704.

33- E. Renard and J. C Justice, A comparison of the conductimetric behavior of cesium chloride in water-tetrahydrofuran, water-dioxane, and water-1,2-dimethoxyethane mixtures, J. Solution. Chem, 1974, 3, 633-647.
34- G. S. Manning, Limiting laws and counterion condensation in polyelectrolyte solutions. I. Colligative properties, J. Chem. Phys. 1969, 51, 924-933 and 934-938.

35- P. Mukerjee and A. K. Ghosh, The effect of urea on methy-lene blue, its self-association, and interaction with polyelectrolytes in aqueous solution, J. Phys. Chem, 1963, 67, 193-197.

36- R. Nandini and B. Vishalakshi, A spectroscopic study of interaction of cationic dyes with heparin, Orbital. 2009, 1, 255-272.

37- W. Essafi, A. Abdelli, G. Bouajila and F. Boué, Behavior of Hydrophobic Polyelectrolyte Solution in Mixed Aqueous/Organic Solvents Revealed by Neutron Scattering and Viscosimetry,Phys. Chem. B. 2012, 116, 13525-13537.

38- W. Essafi, W. Raissi, A. Abdelli and F. Boué, Metastability of Large Aggregates and Viscosity, and Stability of The Pearl Necklace Conformation After Organic Solvent Treatment Of Aqueous Hydrophobic Polyelectrolyte Solutions, J. Phys. Chem. B. 2014, 118, 1227112281.

39- N.J. Rose and R.S. Drago, Molecular addition compounds of iodine. I. An absolute method for the spectroscopic determination of equilibrium constants, J. Am. Chem. Soc. 1959, 81, 6138-6141.

40- TH. C. Singh, R. K. Nath et al, Studies on the interaction of Klebsiella K34 capsular polysaccharide with oppositely charged dyes and surfactants, J. Surface Sci. Technol. 2008, 24, 21-38.

41- P.D. Ross and S. Subramanian, Thermodynamics of protein association reactions: forces contributing to stability, Biochemistry, 1981, 20, 3096-3102. 